\title{
RECENT SEISMICITY IN THE SAN FERNANDO REGION AND TECTONICS IN THE WEST-CENTRAL TRANSVERSE RANGES, CALIFORNIA
}

\author{
By David Hadley and Hiroo Kanamori
}

\begin{abstract}
Since the San Fernando earthquake, February 1971, the density of the southern California seismic array has increased by an order of magnitude. The enhanced coverage provides an ideal setting for the study of the long-term seismicity of the San Fernando aftershock zone and adjacent regions. Most of the recent activity within the San Fernando zone has been thrust faulting at depths shallower than and south of the main shock. One event located slightly deeper than and several kilometers north of the main event suggests shear along a flat plane. Transport of the upper block is south. This event is very similar to another deep, $M_{L}=4.5$, earthquake $30 \mathrm{~km}$ west of San Fernando. If these events are typical of midcrustal deformation, the west-central Transverse Ranges may be a form of decollement. A rapid increase in seismicity $\left(M_{L} \geqq 3.0\right)$ in the region south of San Fernando suggests an increase in regional strain that either was contemporaneous with or immediately followed the San Fernando earthquake.
\end{abstract}

\section{INTRODUCTION}

The San Fernando earthquake of February 9, 1971, $M_{L}=6.4$, and the first three months of aftershock activity have been described in detail by a number of authors (Allen et al., 1971; Hanks et al., 1971; Whitcomb, 1973). The purpose of this paper is to investigate and document the ongoing, long-term nature of this aftershock sequence. The relatively shallow location of this event $(h \sim 13 \mathrm{~km})$ and the high station density provide an ideal setting to monitor the spatial, temporal, and mechanical variations in strain release within both the aftershock zone and the region.

The tectonic setting of the aftershock region is quiet complex. The northwest trending grain of much of southern California is disrupted by the east-west trending Transverse Ranges. At this time it is not clear if these ranges result from the structurally intimate great bend in the San Andreas or if both features are the response to a deeper structural complexity (Hadley and Kanamori, 1977). The southern boundary of the western Transverse Ranges is marked by a gently to steeply north dipping thrust-fault system. The dip-slip offset has been estimated to be as large as 1 to $3 \mathrm{~km}$ (Oakeshott, 1952; Bailey and Jahns, 1954). Recent activity along this fault system is demonstrated by faulted crystalline rocks that rest on Quaternary conglomerates. In addition to the obvious thrust faulting, two other major lineations pass through the aftershock zone. The first lineation is defined by a northeast trending belt of earthquakes that extends from Point Dume to Palmdale. This zone has been described by Whitcomb (1973) and by Hileman (1977). Earthquakes within this zone are interpreted as northeast trending, left-lateral strike-slip events. Seismic activity along the western limb of the San Fernando aftershock area is associated with this belt. The second lineation is the northwest trending, rightlateral San Gabriel fault. Undisturbed sediments northwest of San Fernando cover this fault and indicate that the structure has not experienced significant movement since the Pliocene (Crowell, 1954).

The hypocentral location of the main shock, $34^{\circ} 24.7^{\prime} \mathrm{N}, 118^{\circ} 24.0^{\prime} \mathrm{W}, h \sim 8.4 \mathrm{~km}$, (Allen et al., 1972) has been problematic. The mechanical instrumentation at 
Pasadena recording the signals telemetered from stations of the regional seismic array was subjected to strong ground shaking. This disruption obscured the true arrival at the stations telemetered to Pasadena. The subsequent errors in timing and uncertainty in the crustal velocity model used in the location resulted in standard errors of several kilometers. Teleseismic wave form studies (Langston, 1978) are very sensitive to converted phases reflected from the free surface. Langston's study provides a better constraint on the depth of the initiation of the rupture and added insight into variations in the slip parameters during the event. The wave forms confirm Whitcomb's focal mechanism for the main shock and indicate that rupture started at approximately $13 \mathrm{~km}$ depth on a plane dipping $54^{\circ}$ to the northeast and propagated toward the surface. At a depth of approximately $5 \mathrm{~km}$, the dip of the fault plane shallowed to $30^{\circ}$. The immediate aftershocks studied by Whitcomb suggest a similar shallowing of the fault dip. The seismic moment for the event, from a number of observers (Aki, 1971; Alewine, 1974; Langston, 1978), is I $-2 \times 10^{26}$ dyne-cm.

Previous aftershock studies of this event have been limited to the three months following the main event. As aftershocks are still occurring, this paper seeks to relate systematically present and past seismic activity. We have chosen to exclude from the study events with magnitudes less than $M_{L}=3.5$. This reduces the potential data set from 750 detected events to 125 . Since larger events are better recorded by the regional array, this cutoff effectively limits the study to events that potentially can be accurately located. In addition, the tectonic energy release is controlled by the larger events, and hence the conclusions reached from this subset of events should reflect the ongoing tectonics.

In order to compare the hypocentral locations of past and present earthquakes, all events were systematically relocated. Station delays used in this relocation were primarily determined using the station residuals from a carefully timed and relocated recent event that occurred on October $10,1976, M_{L}=3.9$. This earthquake was well recorded by a dense array and the calculated standard errors for the location are $1 \mathrm{~km}$ horizontally and $2.2 \mathrm{~km}$ vertically. This master event technique minimizes the effects of lateral velocity variations external to the source region (Johnson and Hadley, 1976). The final absolute locations are a function of the master event. The relative spatial distribution of relocated events is largely independent of minor changes in the absolute location of the master event. The velocity model used in the relocation is similar to that derived from the western Transverse Ranges by Hadley and Kanamori (1977). The only major change in the model was the smoothing of velocity contrasts by the addition of several thin layers. This reduces rapid variations in take-off angles for small changes in the depth of the source and tends to stabilize the determination of focal mechanisms. Mechanisms were determined with the aid of a computer program that exhaustively searches the model space (Whitcomb, 1973). This approach provides a quantitative evaluation of the fit of 80 possible slipvectors distributed uniformly over the focal hemisphere.

\section{Spatial and Temporal Location of Activity}

The relocation technique used for the main event was similar to that described above except that $S$ - $P$ intervals from several epicentrally close strong motion instruments (Earthquake Engineering Research Laboratory, 1976) were included in the relocation. The resulting hypocenter is slightly northeast of earlier determinations: $34^{\circ} 25.45^{\prime} \mathrm{N}$ and $118^{\circ} 22.63^{\prime} \mathrm{W}$. The depth has increased to $11.5 \mathrm{~km}$. Standard errors are $1.1 \mathrm{~km}$ horizontally and $2.4 \mathrm{~km}$ vertically. This depth is compatible with 

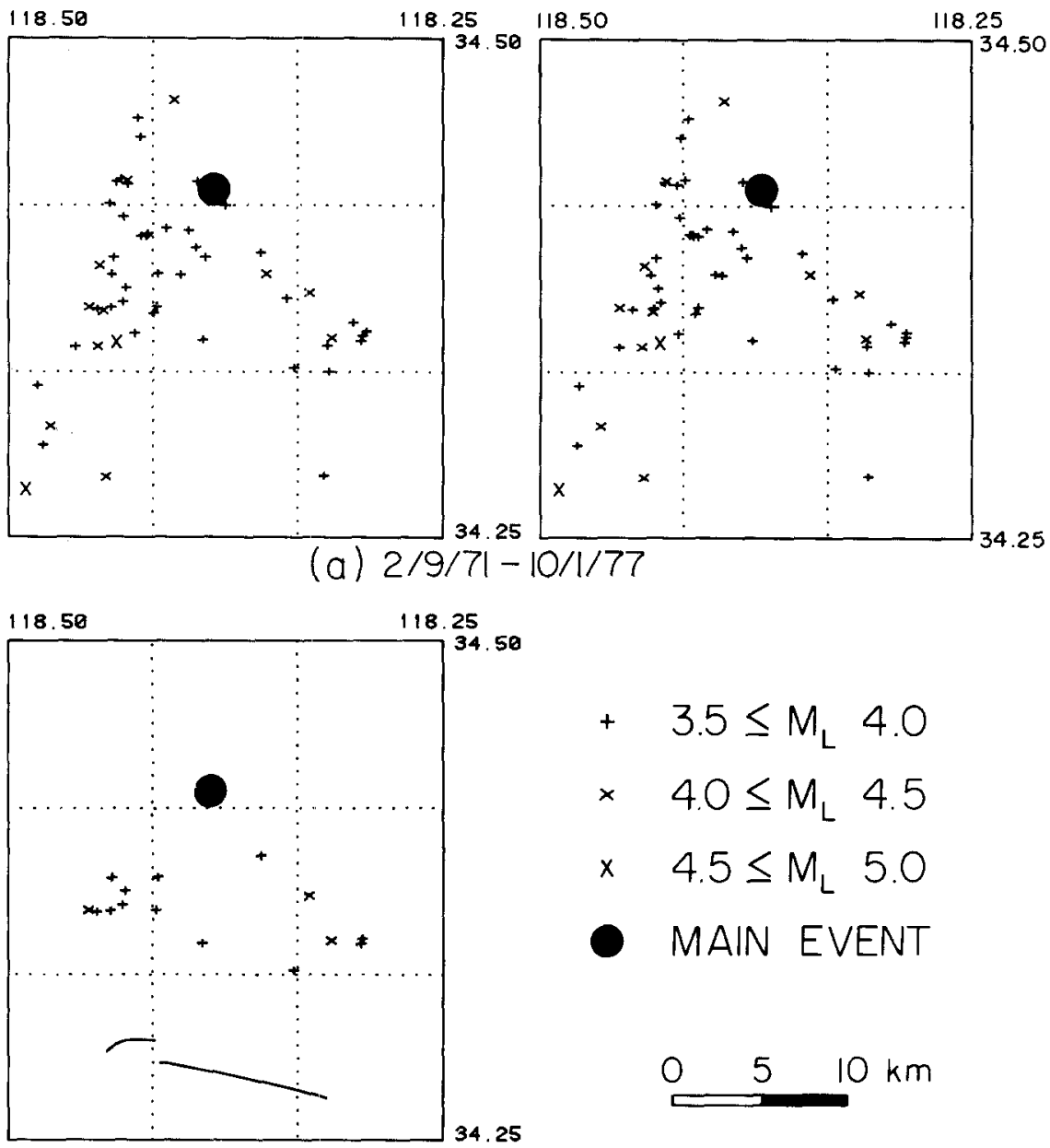

(b) $2 / 9-2 / 10 / 71$

118.50

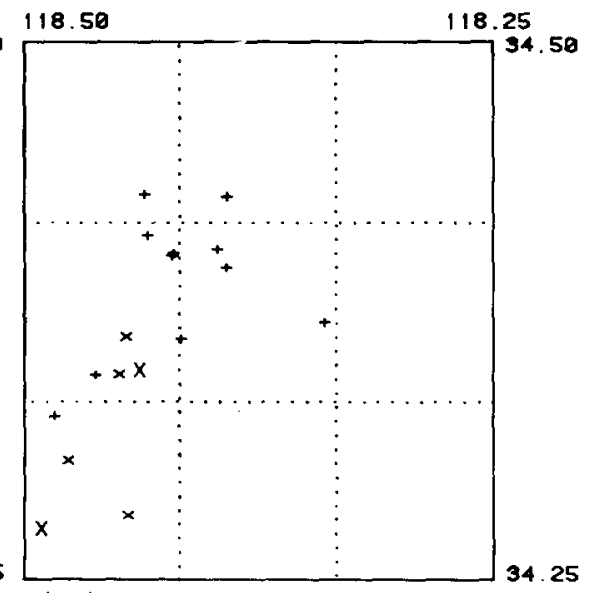

(c) $2 / 10-2 / 20 / 71$

(d) $2 / 20-7 / 1 / 71$

Fig. 1. Epicenters of well-located events for the time periods: (a) $2 / 9 / 71$ to $10 / 1 / 77$, (b) $2 / 9$ to $2 / 10 / 71$, (c) $2 / 10$ to $2 / 20 / 71$, (d) $2 / 20$ to $10 / 1 / 71$. The east-west lines in (b) are the approximate locations of surface faulting. The first plot is a stereo pair. Average standard errors of the events plotted are $2 \mathrm{~km}$ and $3 \mathrm{~km}$ for the horizontal and vertical directions, respectively. 
that determined from teleseismic wave forms. This location is also on the plane defined by aligning Langston's fault geometry with the observed surface faulting.

Figure 1a is a stereo pair showing the hypocenters of all accurately located events. Standard location errors are typically less than $3 \mathrm{~km}$. The following descriptions of the aftershock activity have been divided into four intervals of approximately logarithmically increasing duration.

First day. The well-located events, Figure 1b, outline a triangular region. Unfortunately, many events that occurred during the first day were recorded within the coda of previous events. This resulted in large timing errors and excessively large standard errors. The location of these events are compatible with aftershock activity over the entire triangular region. The fault-plane area defined by surface faulting and the wedge-shaped activity during this interval is $200 \mathrm{~km}^{2}$.

Next 10 days. The area of the aftershock zone has expanded to $300 \mathrm{~km}^{2}$ (Figure 1c). The events locate predominately outside of the region defined by the first day of activity and are north of the surface faulting.

Next 130 days. There is substantial activity along the west limb of the aftershock zone (Figure 1d). This activity includes nine events with magnitudes greater than 4.0 and extends several $\mathrm{km}$ south of the surface faulting. Unlike the thrust mechanisms found for most of the events in other parts of the aftershock zone, these events are left-lateral strike-slip along a plane parallel to the lineation of events (Whitcomb, 1973). The absence of surface faulting suggests that the lateral displacement did not extend to the surface. Furthermore, if the seismicity represents reactivation of an old structure, movement on that fault never has reached the surface, since the San Gabriel fault, passing at a right angle through this zone, is not offset (L. Silver, personal communication).

Using a relationship between seismic moment, $M$, and local magnitude, $M_{L}$, of the form $\log (M)=15+1.7 M_{L}$ (Hartzell and Brune, 1977), we have computed the cumulative seismic moment for the aftershocks located within the San Fernando region (Figure 2). During the interval 0.1 to 10 days the cumulative moment approaches an asymptote. The subsequent burst of activity along the western limb and migration of activity south of the surface rupture are reflected in the moment sum as a break in slope. This rapid increase in strain release and subsequent return to a slowly decaying rate of release, and the change in style of deformation, suggest that this sequence is distinct from the San Fernando earthquake.

Next 2300 days. The seismicity is concentrated in a relatively small subregion southwest of the main shock (Figure 4). Focal mechanisms show considerable variation in the sense of motion. This diversity probably reflects movement on preexisting planes of weakness, such as older faults, which are geometrically favorable for slip but not necessarily aligned with the planes of maximum shear (McKenzie, 1969). Even allowing for such diversity, the region is presently dominated by thrust events. Figure 3 is a north-south cross section through the main event. All earthquake hypocenters computed for this time interval and determined focal planes have been projected onto this section. Three observations are immediately apparent from this projection: (1) most of the recent activity is shallower than the main event; (2) movement on the north dipping plane is consistent in both dip and sense of motion with the main shock; and (3) allowing for the projection of the fault plane of the main event, the shallowest earthquakes west of the main shock are consistently 3 to $5 \mathrm{~km}$ below the inferred main shock fault plane. This suggests either the fault surface has been downstepped to the west, or these events are occurring along deeper, subparallel fractures. 
The focal mechanism of the deepest event, occurring October 17, 1976, is extremely interesting. The depth places this event at the bottom of the seismically active portion of the crust, and can potentially tell us something about the tectonics at this depth. Our preferred choice of fault plane for this event, most consistent with the observed displacement for the main event, is the very shallow, almost flat fault plane (Figure 4). If this event is typical of deformation occurring at midcrustal depths within this province, then the San Gabriel Mountains would be a form of decollement. Movement of the upper block would be to the south.

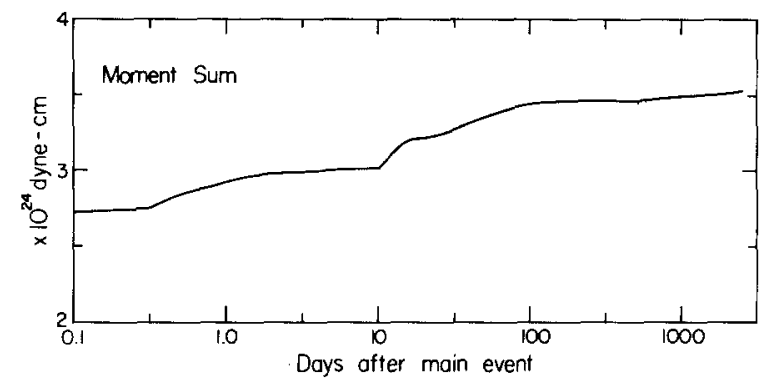

FIG. 2. Cumulative moment sum as a function of logarithmic time for the entire aftershock sequence. The sharp break in slope at 10 days corresponds to the initiation of the predominately left-lateral strikeslip events plotted in Figure 1c.

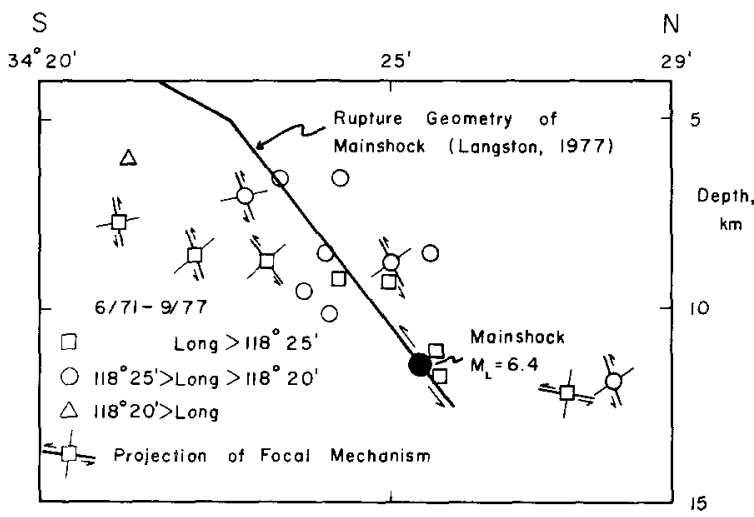

FrG. 3. Projection of hypocenters and focal mechanisms of the recent activity, shown in plan view on Figure 4, onto a north-south plane passing through the main event. The focal planes that pass through the events show the apparent dip as viewed from the east. The arrows indicate the sense of motion on the preferred fault planes.

\section{Regional Tectonics}

The October 17, 1976 event suggests deformation at midcrustal depths on a very shallow, north-dipping structure. A similar model has been previously proposed to account for regional uplift within the Transverse Ranges and the southwestern Mojave (Thatcher, 1976). Although this is certainly a plausible model for the western Transverse Ranges, a single isolated event is not particularly persuasive. However, in April 1976, a sequence of earthquakes located $30 \mathrm{~km}$ west of the San Fernando main shock began with a $M_{L}=4.5$ event. The location of this event is shown on Figure 5, and the focal mechanism data are shown on Figure 6. In this area, distinct from San Fernando, the current seismicity was apparently triggered by a deep $(h \sim 12 \mathrm{~km})$ event. Motion of the upper plate on another near horizontal 
fault plane was southwest. The similarities between this event and the October 1976 earthquake-both occurred at the bottom of the seismic zone and indicate southward transport of the upper block on a subhorizontal fault surface-suggest a regional decollement.

Within southern California, a $P_{n}$ velocity of $7.8 \mathrm{~km} / \mathrm{sec}$ is observed over path lengths of $400 \mathrm{~km}$. This suggests a minimum thickness for this layer of $20 \mathrm{~km}$. By analogy with studies of the adjacent Basin and Range province (Biswas and Knopoff, 1974; Archambeau et al., 1969), this layer is interpreted as an upward extension of the low-velocity zone to the base of the crust. The low upper mantle velocity, depressed from a more typical velocity observed in stable regions of $8.3 \mathrm{~km} / \mathrm{sec}$, is interpreted as the result of partial melting. This interpretation is supported by the observation of a substantial velocity anomaly within a subregion of southen California $(7.8 \mathrm{~km} / \mathrm{sec}$ versus $8.3 \mathrm{~km} / \mathrm{sec}$, Hadley and Kanamori, 1977). If this anomaly

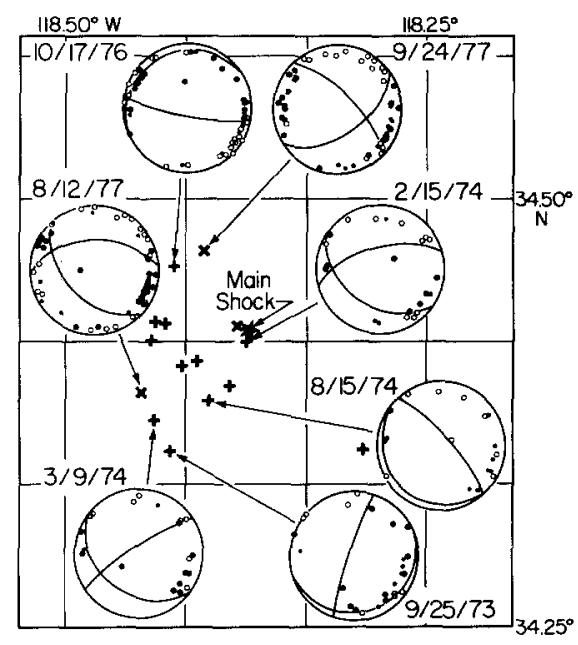

FIG. 4. Hypocenters and local mechanisms for the period $7 / 1 / 71$ to $10 / 1 / 77$. The stereonet projections are lower hemisphere and the solid circles are compression. The deepest event in this sequence, occurring on $10 / 17 / 76$, suggests southward movement of the upper block on a near horizontal plane.

resulted from a phase change such as garnet-granulite to eclogite a large gravity anomaly would be observed. The absence of any anomaly indicates that the velocity contrast is not accompanied by a significant density contrast. Anderson and Spetzler (1970) have shown that a 1 per cent partial melt can produce the observed velocity contrast. Such a small melt fraction will not affect the gravity. From previous studies (Hadley and Kanamori, 1977; Raikes and Hadley, 1977) there is strong evidence for regional decoupling that is accompanied by large variations in slip direction between the crust and upper mantle. The shallow upper mantle, interpreted as a zone of partial melting, has been suggested as the zone of decoupling. Recent studies of the temperature and compositional effects on the transition from brittle to ductile yielding (Brace and Byerlee, 1970; Byerlee and Brace, 1968) show that these variables may control the depth of the seismic zone within California. Events occurring at the bottom of the seismic zone may be indicative of aseismic deformation within the lower crust. The recent deep seismicity supports the hypothesis of regional shear parallel to a horizontal plane and further suggests that this deformation may not be limited to the upper mantle.

The San Fernando earthquake represents the end result of strain accumulation within the crust. The co-seismic crustal deformations south of San Fernando, 
considered from either an observational or theoretical base, were small (Alewine, 1973; Castle et $a l ., 1975$ ). The small strain changes require a relatively small change in stress. If the San Fernando earthquake was the result of very gradual strain accumulation, the regional variations in fault strength and the stress field would control the occurrence of faulting. A regional change in seismicity, particularly in a region not strained by the main shock, would not be expected. Alternatively, if the stress field changed abruptly, a regional increase in seismicity would be expected. The San Fernando event would represent one of many faults rapidly loaded to

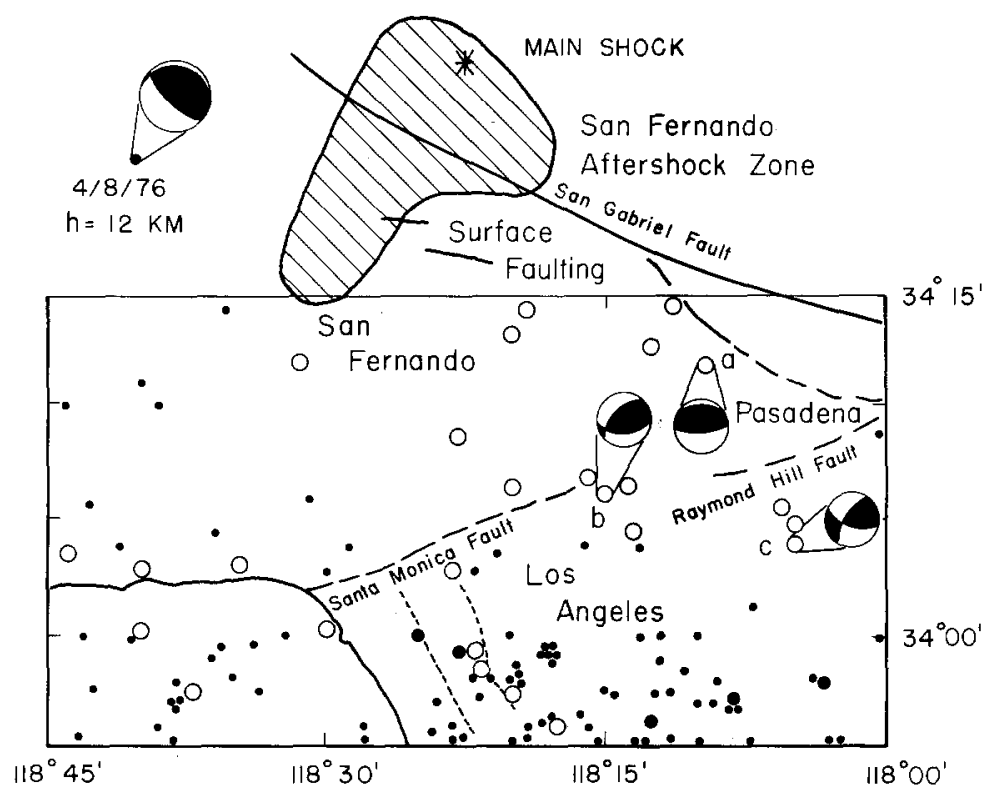

Fig. 5. Earthquake epicenters $\left(M_{L} \geqq 3.0\right)$ for the region south of the San Fernando aftershock zone. The events are divided in time by the San Fernando main shock. The lack of activity in the region around and west of Pasadena in the time interval 1932 to 1970 (solid circles), and the subsequent occurrence of many events (1971 to September 1977, open circles) suggests a recent increase in the shear stress. Focal mechanism data for the events shown are plotted in Figure 6.

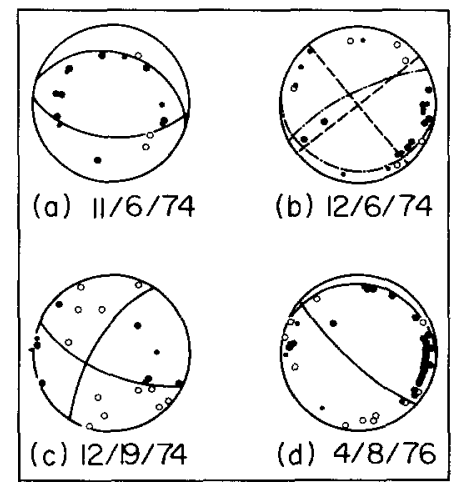

FIG. 6. Focal data for the mechanisms plotted in Figure 5. An alternate solution is shown for event B. The projections are lower hemisphere and solid circles are compressional.

failure. Figure 5 is a plot of seismicity, $M_{L} \geqq 3.0$, in the region south of San Fernando. The solid symbols are earthquake locations from 1932 through 1970. Open circles are from 1971 to September 1977. Seismicity within the Los Angeles Basin shows no increase. However, activity along the southern boundary of the Transverse Ranges, 
namely at the eastern end of the Santa Monica fault and in the vicinity of the Sierra Madre and Raymond Hill faults, shows a marked increase. The available focal mechanisms for these events, with some diversity, are oblique thrust (Figure 6).

The apparent increase in seismicity within this zone of the Transverse Ranges suggests a recent, significant increase in the regional stress. Consistent with this interpretation is the report of Savage and Prescott (1977) of "one east-west geodimeter line near Palmdale... [that shows] ... a striking increase in length in the period 1968-1971, a possible precursor to the 1971 San Fernando earthquake." From regional horizontal and vertical geodetic data, Thatcher (1976) similarly concludes that the central Transverse Ranges have recently experienced an episodic strain accumulation.

\section{CoNCLUSION}

We have systematically relocated the San Fernando main shock and all $\left(M_{L} \geqq\right.$ 3.5) aftershocks. The cumulative moment sum for the aftershocks shows two distinct sequences of activity. The change in the rate of strain release is accompanied by extension of activity southwest of the surface faulting and by a change in style of faulting from thrust to strike-slip (Whitcomb, 1973). Recent activity is clustered slightly southwest of the main shock epicenter. The deepest event within the recent activity as well as a separate earthquake $30 \mathrm{~km}$ west of the San Fernando earthquake suggest a form of decollement. The relatively abrupt change in seismicity in the region south of the aftershock zone suggests a rapid increase in the stress field. This implies that San Fernando was only one of many faults recently loaded to failure. We speculate that the increase in regional stress is intimately related to inferred aseismic deformation within the lower crust and upper mantle. The few deep events studied to date suggest that this deformation is a horizontal shear with a relative southward transport of the upper portion of the crust.

\section{ACKNOWLEDGMENTS}

We thank Lee Silver for stimulating discussions on southern California tectonics. Jim Whitcomb provided phase data for the period 1971 to 1973 . This research was supported by the U.S. Geological Survey under Contract 14-08-0001-16711.

\section{REFERENCES}

Aki, K. (1971). Seismic moment and stress drop, presented at the Annual Meeting of the Seismological Society of America, The San Fernando Earthquake of February 9, 1971, A Symposium, Riverside, California.

Alewine, R. (1974). Application of linear inversion theory toward the estimation of seismic source parameters, Ph.D. thesis, California Institute of Technology.

Allen, C. R., G. R. Engen, T. C. Hanks, J. M. Nordquist, and W. R. Thatcher (1971). Main shock and larger aftershocks of the San Fernando Earthquake, February 9 through March 1, 1971, U.S. Geol. Surv. Profess. Paper 733, 17-20.

Allen, C. R., T. C. Hanks, and J. H. Whitcomb (1972). Seismological studies of the San Fernando Earthquake and their tectonic implications, Calif. Div. Mines Bull. 196, Ch. 20.

Anderson, D. L. and H. Spetzler (1970). Partial melting and the low-velocity zone, Phys. Earth Planet Interiors 4, 62-64.

Archambeau, C. B., E. A. Flinn, and D. G. Lambert (1969). Fine structure of the upper mantle, $J$. Geophys Res. 74, 5825-5865.

Bailey, T. L. and R. H. Jahns (1954). Geology of the Transverse Range province, Southern California, Calif. Div. of Mines Bull. 170, 83-106.

Biswas, N. N. and L. Knopoff (1974). The structure of the upper mantle under the United States from the dispersion of Rayleigh waves, Geophys. J. 36, 515-539.

Brace, W. and J. Byerlee (1970). California earthquakes: Why only shallow focus?, Science 168, 1573.

Byerlee, J. and W. Brace (1968). Stick-slip, stable sliding and earthquakes-effect of rock type. pressure, strain rate and stiffness, J. Geophys. Res. 73, 6301. 
Castle, R. O., J. P. Church, M. R. Elliott, and N. L. Morrison (1975). Vertical crustal movements preceding and accompanying the San Fernando Earthquake of February 9, 1971, Tectonophysics 29, 127-140.

Crowell, J. C. (1954). Geology of the Ridge Basin area, Los Angeles and Ventura Counties, Calif. Div. of Mines Bull. 170, Map Sheet No. 7.

Earthquake Engineering Research Laboratory (1976). Strong motion earthquake accelerograms, Report EERL 76-02, California Institute of Technology, Pasadena.

Hadley, D. and H. Kanamori (1977). Seismic structure of the Transverse Ranges, California, Bull. Geol. Soc. Am. 88, 1469-1478.

Hanks, T. C., T. H. Jordan, and J. B. Minster (1971). Precise locations of aftershocks of the San Fernando Earthquake 2300 (GMT) February 10-1700 February 11, 1971, U.S. Geol. Surv. Profess. Paper 733, 21-23.

Hartzell, S. H. and J. N. Brune (1977). Source parameters for the January, 1975 Imperial Valley-Brawley Earthquake swarm (in press).

Hileman, J. A. (1977). A contribution to the study of the seismicity of Southern California, Ph.D. thesis, California Institute of Technology.

Kanamori, H. and D. M. Hadley (1975). Crustal structure and temporal velocity change in Southern California, Pageoph 113, 257-280.

Johnson, C. E. and D. M. Hadley (1976). Tectonic implications of the Brawley Earthquake swarm, Imperial Valley, California, Bull. Seism. Soc. Am. 66, 1133-1144.

Langston, C. A. (1978). The February 9, 1971 San Fernando Earthquake: A study of source finiteness in teleseismic body waves, Bull. Seism. Soc. Am. 68, 1-29.

McKenzie, D. P. (1969). The relation between fault-plane solutions for earthquakes and the directions of the principal stresses, Bull. Seism. Soc. Am. 59, 591-601.

Oakeshott, G. B. (1952) Geology and mineral deposits of the San Fernando Quadrangle, Los Angeles County, Calif. Div. Mines Bull. 172, 89-105.

Raikes, S. A. and D. M. Hadley (1977). Azimuthal variation of teleseismic P-residuals in Southern California: Implications for upper mantle structure (in press).

Savage, J. C. and W. P. Prescott (1977). Geodimeter measurements on the Palmdale Bulge, 1959-77 (abstract), EOS 58, 1121.

Thatcher, W. (1976). Episodic strain accumulation in Southern California, Science 194, 691-695.

Whitcomb, J. H. (1971). Fault-plane solutions of the February 9, 1971, San Fernando Earthquake and some aftershocks, U.S. Geol. Surv. Profess. Paper 733, 30-32.

Whitcomb, J. H. (1973). The 1971 San Fernando Earthquake series focal mechanisms and tectonics, Ph.D. thesis, California Institute of Technology.

\author{
Division of Geological and Planetary Sciences \\ California Institute of Technology \\ Pasadena, California 91125 \\ Contribution No. 3018
}

Manuscript received January 12, 1978 